\title{
Individualidade e Sociabilidade
}

\author{
Felix Wiesjahn'
}

\section{Introdução}

A minha pergunta fundamental neste ensaio será "O que é o homem?". Como trata-se de uma questão profundamente filosófica, sei que nunca ninguém conseguirá respondê-la de maneira satisfatória. O papel da filosofia é isso, perguntá-lo teimosamente às ciências, jamais satisfazendo-se com as propostas e respostas que elas oferecem. Este relacionamento entre a filosofia e as ciências, que é frutífero devido a seu caráter dialético, surge porque cada ciência reduz a pergunta fundamental a uma versão limitada ${ }^{2}$, enquanto que a filosofia procura uma resposta integral. Assim, a biologia, por exemplo, questiona-se a respeito do funcionamento do corpo humano, a medicina procura formas de se prolongar a vida; as ciências humanas pesquisam os ramos da cultura e sociedade, ou seja, a posição "extraordinária" do homem no mundo. Minha pergunta sociológica baseia-se na pergunta "O que é o homem?" reduzindo-a, ao mesmo tempo. Nesse sentido, a pergunta seria, por exemplo: "Qual é o papel da sociedade na formação do indivíduo?"3.

Em geral, a ciência pode atualmente ser dividida em duas diferentes áreas. Primeiro há, de um lado, os estudos sobre a natureza, incluindo o corpo humano. As ciências exatas e biológicas são responsáveis por perguntas desse tipo. A segunda área abrange a sociedade e, consequentemente, o próprio ser humano. Aqui aparecem as chamadas ciências humanas. Elas se subdividem em trabalhos a respeito da sociedade ou do indivíduo. É claro que não é possível delimitar essas áreas, separando-as umas das outras, sem que se caia em generalizações, pois não existem fronteiras exatas entre elas. Ao contrário, só o conjunto de todas as ciências, formado mediante a queda dos muros entre elas, poderia possibilitar verdadeiros conhecimentos sobre nós e sobre o mundo. Mas isto permanecerá um ideal, talvez nunca realizado. Devemos, por isso, contentar-nos com conhecimentos que só representam objetos de pesquisa incompletos. Um bom exemplo destes conflitos e tensões é o próprio ser humano. Ele é objeto de pesquisa em todas as áreas da ciência, mas tanto as

\footnotetext{
'Estudante visitante do Depto, de Ciências Sociais/UFPR.

${ }^{2}$ Isto não significa que as respostas a tais perguntas limitadas possam chegar a um nível satisfatório: sempre surgirão novos fatos ainda inexplicados. Poder-se-ia formular, imediatamente, uma definição do homem: o homem é este ser que tenta explicar sua existência, embora saiba que nunca o conseguirá; ou até receie que, na verdade, não tem nada a explicar.

${ }^{3}$ Essa pergunta é uma entre várias possíveis, que serve neste instante apenas a exemplificar um princípio.
} 
respostas à pergunta fundamental "O que é o homem?", como à pergunta sociológica "Como funciona o conjunto dos homens?" ainda não podem ser integradas para oferecer uma imagem única. Como atuam a natureza exterior, o corpo humano e a cultura (linguagem, tecnologia, arte), no processo de formação da sociedade? Qual é o papel da sociedade neste processo formativo? Essas (grosseiramente formuladas) perguntas e muitas outras estão longe de ser respondidas. $\mathrm{O}$ avanço da tecnologia, que possibilita a clonagem de seres vivos, as modificações dos genes, a criação de mundos virtuais e de máquinas minúsculas e invisíveis, dificulta ainda mais a distinção do papel da natureza e da cultura.

\section{Esboço das idéias fundamentais de Norbert Elias sobre o relacionamento de sociedade e indivíduo}

Pretendo, a seguinte, tratar da questão do relacionamento entre individualidade e sociabilidade, um problema que sempre tinha chamado o interesse de Norbert Elias. Como ele, no decorrer da sua longa vida, não só publicou pensamentos sobre este assunto em vários livros e contextos bastante diferentes, mas também desenvolveu sua opinião ao repensar e mudar seus próprios argumentos, o meu trabalho não pretende ser uma crítica sistemática da obra de Elias. Antes, pelo contrário, as idéias de Elias serão os meus pontos de partida e inspiração, dos quais tentarei pensar de novo sobre as perguntas por ele colocadas e, no melhor dos casos, superarei suas respostas. Subo aos ombros de um gigante.

Norbert Elias tentou acabar com a separação entre as perguntas sobre o ser humano, de um lado, e sobre a sociedade, de outro ${ }^{4}$. Conceitos como indivíduo, mente ou consciência não podem ser entendidos separados da sociedade; e sociedade, nação ou povo são conceitos que só fazem sentido em relação ao indivíduo, segundo ele. Assim, a resposta à pergunta "O que é o homem?" sempre tem um caráter duplo: individual e social, conceitos que não podem ser entendidos separadamente. Porém, nos últimos anos a tecnologia genética despertou esperanças quanto à possibilidade de separação dos fatores individuais (quer dizer, genéticos) dos fatores sociais, no processo da formação

\footnotetext{
${ }^{4} \mathrm{O}$ abismo ainda mais profundo, que separa as ciências humanas das ciências exatas, não foi superado por Elias, e, como avalio, ele nem tentou fazê-lo, embora, por exemplo, a ocupação com a mente humana deveria levar em consideração os resultados das ciências neurológicas. Quer seja em relação ao fato de que estas ciências só nos últimos anos alcançaram um nível de conhecimento cada vez mais alto (válido também e sobretudo para a genética; veja: Folha de São Paulo, 26 de outubro, pág. C 6), quanto ao fato de que é impossível considerar "o todo" dos conhecimentos numa obra só, podem "explicar" essa "falta" nas pesquisas de Elias. Porém, ele tinha consciência da "imbricação mútua e da interdependência entre natureza, sociedade e indivíduo". Norbert Elias, Sobre o Tempo, Rio de Janeiro, 1998, pág. 17.
} 
do caráter individual. Mas essa tecnologia nova ainda não oferece resultados que poderiam servir de esclarecimento à nossa pergunta.

Ora, para Elias o lado social tem preponderância no processo formativo do indivíduo, já que para ele o ser humano é principalmente o entrelaçamento e as ligações que este tem com outros indivíduos, com as coisas, com o mundo e com si mesmo, ou seja, a realidade individual não está só composta pelas ações individuais, mas também (ou até principalmente) pelas ações sociais ${ }^{5}$. Isto seria uma amplificação da definição acima: o indivíduo não é só os entrelaçamentos e as ligações que estabelece, mas também os entrelaçamentos e as ligações que os outros estabelecem a respeito dele. "Ser humano" é uma categoria que resulta incompreensível se procurada no exemplo individual; é apenas manejável em relação ao conjunto dos indivíduos. Evitando um problema fundamental da epistemologia, a identidade do sujeito e do objeto de pesquisa, Elias pode assim argumentar a favor de sua teoria sobre o processo civilizador. "Seria difícil compreender o homem em sua totalidade, se primeiro o imaginarmos vagando sozinho pelo mundo e apenas secundariamente adaptando sua conduta à dos outros homens" ${ }^{\prime 6}$. De outro lado Elias pode, ao olhar para fatos considerados sociais, como por exemplo a língua, fornecê-los com um efeito individualizado. "Como meio de comunicação utilizado por uma multiplicidade de seres humanos, a língua já existe no momento em que um indivíduo aprende a se valer dela. Assim, não é despropositado falarmos aqui de uma individualização da língua", ${ }^{\text {.7 }}$ Um pouco mais adiante, Elias generaliza este pensamento: "O fato de os homens deverem e poderem se orientar em seu mundo adquirindo um saber, e de, com isso, sua vida individual e coletiva depender totalmente da aprendizagem de símbolos sociais, é uma das particularidades que diferenciam o ser humano de todos os outros seres vivos"

Um outro fato importante no pensamento de Elias, é que apenas em uma perspectiva histórica estados sociais e comportamentos individuais podem ser explicados. Eis porque na obra deste autor se juntam idéias e métodos de

\footnotetext{
5 "Ações sociais" significam aqui simplesmente tudo aquilo que não vem do "eu", mas dos "outros" e do conjunto dos indivíduos. Mais adiante falarei sobre a questão da autonomia individual, que surge na medida em que nos damos conta de que somos também as ligações, relações e entrelaçamentos que os outros têm conosco. Existe uma diferença entre meu uso das palavras "indivíduo" e "eu". Enquanto "indivíduo" é um conceito neutro, designando cada ser humano, "eu" significa algo mais subjetivo. Usarei "eu" para expressar os sentimentos interiores do indivíduo. Assim, "indivíduo" é o ser humano visto de fora, e "eu" o de dentro. Essa separação simplifica a realidade (e Elias diria que a questão em si é falsa), mas como demonstrarei no capítulo 3, existem estes dois pontos de vista, embora não possam ser separados um do outro. A separação artificial só facilita o entendimento do caráter dual do ser humano.
}

${ }^{6}$ Ibid., pág. 19.

${ }^{7}$ Ibid., pág. 20.

${ }^{8}$ Ibid. 
diferentes campos, de áreas científicas antigamente separadas: idéias e métodos da sociologia, da antropologia, da ciência política, da história, da economia e da psicologia. Por fim, tenho de mencionar que neste modo de pesquisa, teoria e aplicação são difíceis de diferenciar. A especificidade de cada situação histórica, seja de Mozart, seja das sociedades de corte européias, ou seja da formação e do desenvolvimento de nações, não permite a aplicação de uma única teoria, mas requer continuamente uma nova tentativa epistemológica. Tanto a crença segundo a qual a história (e a arte) teriam sido as mesmas sem os indivíduos, que nelas atuaram - como por exemplo Luis XIV, Mozart - como a crença de que sem estes indivíduos a história (e a arte) teriam seguido por um caminho muito diferente, ambas as crenças são erradas.

Elias também considera o papel distinto da natureza quando formula algo assim: "As regularidades imanentes às configurações sociais não são idênticas às regularidades da "mente", do raciocínio individual, nem às regularidades do que chamamos de "natureza", mesmo que, funcionalmente, todas essas diferentes dimensões da realidade estejam indissoluvelmente ligadas entre si" ${ }^{\prime}$. Como essas regularidades são ao mesmo tempo ligadas entre si e diferentes, só uma ilustração "com referência a mudanças específicas e empiricamente demonstráveis"10, quer dizer um exemplo concreto, pode esclarecê-las. Num outro texto, ele fala sobre a falta de uma teoria geral, mas também não pode pôr à disposição do leitor, ou da comunidade científica em geral, mais do que as imagens equívocas de "pedra e casa" e de "nota e melodia", que, no que diz respeito à sociedade e ao indivíduo, não fazem muito sentido. Pois que nestas imagens, "casa" e "melodia" são os fins e "pedra" e "nota" os meios, e a pergunta de meio e fim não é adequada em se tratando de sociedade e indivíduo. $\mathrm{O}$ valor dessas imagens consiste em chamar atenção ao fato de que "o todo é diferente da soma de suas partes"" Além disso, elas ajudam a esclarecer a diferença ontológica entre substância e relacionamento e explicam assim a preferência de Elias pelos últimos. Elias favorece o exame dos relacionamentos, embora pareça mais fácil pesquisar substâncias e entidades estáveis. Ele diz que, para compreender os fenômenos sociais, "é necessário desistir de pensar em termos de substâncias isoladas únicas e começar a pensar em termos de relações e funções" melodia" apoia essa preferência do relacionamento em comparação à substância, já que uma melodia é reconhecível em todas as tonalidades, quer dizer, que as notas isoladas e a tonalidade em que a melodia é realizada - as

\footnotetext{
${ }^{9}$ Norbert Elias, O Processo Civilizador 1I: Formação do Estado e Civilização. Rio de Janeiro, pág. 194.

${ }^{10}$ Ibid., pág. 195.

"Ibid.

${ }^{12}$ Ibid., pág. 25.
}

Renciles Yremirute 
substâncias por assim dizer - desempenham um papel bem menor do que o relacionamento entre as notas. O significado de uma nota solitária é completamente dependente de seu contexto, pois cada nota pode desempenhar qualquer papel numa melodia. O mesmo vale para a imagem da "casa" e "pedra". O relacionamento entre os tijolos, a planta da construção por assim dizer, contém informações ontológicas muito mais ricas sobre cada tijolo, do que a contemplação de um só tijolo pode oferecer. Mesmo sob risco de me repetir: não se pode esquecer que a contemplação de um indivíduo afastado não é possível, pois o indivíduo está envolvido numa rede social da qual não se pode desligar.

Apesar do fato que mencionei agora - várias deficiências da obra de Norbert Elias - acho que suas análises são, em geral, convincentes. A obrigação de juntar os conceitos de sociedade e indivíduo, a impossibilidade de uma sociedade sem indivíduos ou de um indivíduo a-social, a vaidade de se tentar entender a sociedade sem encarar o indivíduo dentro dela e vice-versa, e por fim a importância da realidade histórica do objeto da pesquisa ficam muito evidentes na obra de Elias.

\section{O duplo caráter do indivíduo: social e solitário}

Como acabei de demonstrar, não faz muito sentido pensar os conceitos de sociedade e indivíduo separadamente. Porém, existe um outro lado do indivíduo, que colocarei como "eu". O "eu" não só percebe-se no dia-a-dia como uma entidade afastada das outras ${ }^{13}$ e não como uma parte decisiva de uma casa ou de uma melodia, mas também é (como corpo biológico) solitário e afastado num certo sentido, ou seja, "será preciso levarmos em conta o fato de que os seres humanos, que representam um nível altíssimo - talvez o mais altode integração e diferenciação, surgiram do universo físico" "14. As ligações entre o "eu" e o mundo compõem-se das informações transmitidas pelos sentidos. Estes são corporais, individuais e limitados na sua capacidade de oferecer conhecimentos de confiança. O paradoxo, que se forma através das tensões entre o olhar objetivo da ciência e o olhar individual, é composto pelo "indivíduo" como parte da sociedade a um lado e pelo "eu" como entidade isolada, a outro. A ciência tem como objetivo a representação e a compreensão da realidade. Como o sentimento de afastamento do "eu" faz parte da realidade, não só da realidade individual mas também da realidade comum, a ciência, e neste caso a teoria sobre a sociedade dos indivíduos, tem que considerar este fato e tem que procurar uma solução para este paradoxo. São ambas realidades:

\footnotetext{
13 Parece impossível verificar essa hipótese, mas é nela que vou fundamentar a minha argumentação.

${ }^{14}$ Ibid., pág. 12. 
o indivíduo que só pode ser entendido em conjunto com a sociedade, e o "eu" que se sente solitário e longe da influência de um "nós". Ainda que este último sentimento seja um engano, é um sentimento real, freqüente e comum e merece, por isso, um lugar nos pensamentos sobre o ser humano.

Vou agora aproximar-me deste problema ao examinar três diferentes campos da existência humana, nos quais surgem conflitos entre os conceitos de "eu"e de "indivíduo".

\subsection{A criança}

Primeiro, é preciso mencionar dois fatos fundamentais: uma criança nasce a-social, quer dizer, sem nenhum conhecimento ou saber sobre o mundo humano; entretanto nasce dentro de uma estrutura social já existente ${ }^{15}$. Essa estrutura social é composta da língua e das "regras de controle das pulsões e dos afetos que são próprias de uma civilização"16 , como Elias diz. Então, "uma criança só se torna um ser humano ao se integrar num grupo"17. Essa afirmação é, abstraindo seu caráter radical, uma definição negativa do ser humano, pois, antes de integrar-se em um grupo, a criança ainda não merece a designação de "ser humano". É claro que isto não é satisfatório, porque temos a plena consciência de que até o recém-nascido faz parte da espécie "ser humano". Como, por outro lado, a aprendizagem do comportamento social é necessária para a sobrevivência ${ }^{18}$, poderíamos dizer que o indivíduo perde nos primeiros (três, cinco, dez ?) anos grande parte da sua individualidade. Assim, a infância é um estado excepcional na vida humana ${ }^{19}$, a fase da socialização. Todas as funções humanas, que não são legadas hereditariamente, têm que ser aprendidas nessa fase. O ser humano então nasce incapaz de sobreviver, para que ele possa aprender (no mundo, na sociedade) as necessidades de sobrevivência. Essas são funções da situação histórica (para aplicar a terminologia matemática), como cada estado histórico requer outras e novas faculdades do homem. Só graças a este fato foi possível a dispersão do homem

\footnotetext{
${ }^{15}$ Seja qual for a resposta à pergunta teológica "quando a vida começa?", vou, para facilitar, definir que a vida começa com o parto, ainda que saiba que já no ventre materno a criança está estampada pelo mundo de fora.

${ }^{16}$ Norbert Elias, Sobre o tempo, Rio de Janeiro, 1998, pág. 18.

${ }^{17} \mathrm{Ibid}$.

${ }^{18}$ Nem isto é plena verdade: penso nos deficientes mentais, que, no decorrer dos últimos séculos, ganharam a possibilidade de sobreviver, embora só sejam capazes de aprender um comportamento social muito restrito. São seres humanos sem dúvida. Temos então que constatar que excepções são possíveis. Este paradoxo pode ser formulado assim: o homem é este ser, que permite a existência de exemplares da espécie dele, que não cumprem a definição do homem, pois não aprendem um comportamento social. A excepção confirma a regra.

${ }^{19} \mathrm{O}$ relacionamento direto com o ambiente, a irresponsabilidade, o caráter onírico e outra caraterísticas da vida infantil perdem-se ao decorrer do crescimento.
} 
na terra e um desenvolvimento cultural, pois cada nova geração (ou até cada indivíduo) aprende regras sociais, normas de conduta e línguas insignificantemente diferentes. A acumulação dessas diferenças minúsculas possibilita o funcionamento contínuo do processo civilizador.

A aprendizagem infantil de uma língua ${ }^{20}$, que é uma marcada caraterística do homem, revela muito bem o processo da socialização no indivíduo. Para este, a língua tem dois efeitos: "Ao aprenderem uma primeira língua $[\ldots]$ as crianças têm acesso ao mundo simbólico. Elas abrem para si próprias a possibilidade de adquirir mais conhecimento, mais experiências simbolizadas. Mas a língua que aprendemos quando crianças limita também pode mesmo bloquear - as oportunidades de realizar experiências e adquirir conhecimento. [...] A língua abre a porta para o mundo simbólico de um modo fortemente seletivo e, assim, de um modo limitador" ${ }^{21}$. Assim, o modo habitual de dizer que uma criança aprende a falar não é correto, pois ela aprende sobretudo a língua de uma sociedade particular. O fato de existirem várias línguas espalhadas no tempo e no espaço, também deixa claro como funciona o processo civilizador. Cada sociedade e cada geração fala (mais ou menos) diferentemente e tem, por isso, um acesso diferente ao mundo com as limitações particulares deste acesso. Ao introduzir a teoria simbólica deste último, Elias fundamenta a variabilidade das línguas biologicamente, e chega assim à ponte de onde se pode explicar o crescimento do conhecimento: "A imensa variabilidade de padrões sonoros, que os seres humanos podem produzir como meios de comunicação, é uma das condições da variabilidade das línguas. É também uma condição do crescimento de conhecimento. Sem as mudanças inovadores dos padrões sonoros de uma língua, não seriam possíveis as mudanças inovadores do conhecimento"22. O indivíduo pode aí desempenhar o papel de inovar, introduzir, usar e, assim, confirmar novos conceitos simbólicos ou de esquecer e eliminar velhos conceitos. Considerando todos os argumentos aqui desenvolvidos, fica também claro que este papel individual é restrito e limitado.

\subsection{A liberdade 23}

\footnotetext{
${ }^{20}$ O que será dito a seguir sobre a língua tem em maior parte também validade para as "linguagens" das regras sociais e das normas de conduta.

${ }^{21}$ Norbert Elias, Teoria simbólica, Oeiras, 1994, pág. 129.

${ }^{22}$ Ibid., pág. 5 .

${ }^{23}$ Existem diferentes tipos de liberdade. A liberdade de escolher entre duas possibilidades (sim/não; PT/PFL;...) só é uma liberdade aparente, pois ao escolher o "sim", o "não" já é definido e escolhido negativamente. No outro extremo está a liberdade total, a liberdade de, por exemplo, recusar as decisões entre o "sim" e o "não". O meu conceito de liberdade oscila entre estes dois extremos, pois tanto a liberdade aparente como a liberdade total são conceitos ideais.
} 
O segundo campo da existência humana do qual me proponho a tratar, é a questão da liberdade ou autonomia individual. Depois das argumentações acima, parece que esses bens não fazem parte da vida do homem, ou, se fazem, só muito restritamente. Mas este é o olhar da ciência. Em contrapartida, existe o olhar do "eu", a cujo caráter aludi na parte 3 . No que diz respeito ao sentimento do "eu", de ser uma entidade afastada do mundo e, assim, de ter a faculdade de atuar liberalmente, a pergunta não pode ser se estes sentimentos são verdadeiros ou realistas, mas como este "engano" (coloco-o em aspas porque não tenho certeza de que o é) de se acreditar em uma autonomia própria funciona, e qual é o significado desse sentimento para o indivíduo e para a sociedade.

Acredito que o duplo caráter do homem - o lado social e o lado biológico - é a raiz deste engano. Como o nosso corpo é individual, todos os nossos sentimentos corporais são individuais e indivisíveis. A possibilidade do suicídio é com certeza um dos fundamentos do nosso sentimento de "ser autônomo". Podemos dizer então que o ser humano tem uma certa autonomia no que diz respeito ao seu corpo. Porém, não é só isso; já que acreditamos também que podemos decidir, pelo menos num certo quadro, nosso comportamento social. Segundo Elias, não existe tal liberdade de conduta, porque nascemos e socializamo-nos dentro de uma estrutura já existente, que determina o que podemos pensar e como podemos nos comportar. Essa determinação não é completa, pois isto significaria que mudanças sociais não seriam possíveis. Mas a estrutura já existente, a situação histórica para assim dizer, determina o quadro dos comportamentos possíveis. A socialização, que sempre reflete a situação histórica, traça fronteiras em volta da nossa liberdade ${ }^{24}$, como também a nossa estrutura biológica não permite qualquer tipo de comportamento (não podemos voar, por exemplo). É extremamente difícil dizer se o poder da socialização é total ou se "sobram" alguns campos de liberdade ao indivíduo. Acredito que este último possui certas reservas de autonomia, cuja intensidade/amplitude depende de sua socialização, quer dizer, de todas as regras e normas sociais vigentes na época histórica em que ele vive, e do próprio indivíduo. Mas a socialização tem a preponderância aqui, pois a relação histórica entre liberdade e necessidade define as margens individuais de comportamento. Por isso, uma teoria geral sobre essa pergunta não é possível. Quero só apontar para um paradoxo: se as regras e normas vigentes em uma sociedade são orientadas à autonomia individual, como se pode distinguir entre autonomia individual e socialização?

Questionei-me, no início deste parágrafo, a respeito do significado dos sentimentos de liberdade para o indivíduo e para a sociedade. Não posso

${ }^{24}$ É claro que existem sempre indivíduos que atravessam essas fronteiras sociais. Conforme a situação histórica, eles são chamados de deficientes, loucos, terroristas ou artistas.

Preniler Yromicule 
responder a essa pergunta, mas continuo achando-a muito interessante. Assim, deixo-a em suspenso, sem resposta.

\subsection{A morte}

Fica muito óbvio o duplo caráter do ser humano, em se tratando da morte. Embora ela seja um fato (um fim) natural, pode e deve ser pensada culturalmente; o ser humano sabe, desde a adolescência pelo menos, que vai morrer. Acrescente-se a isso que a morte também é um fato individual, pois um indivíduo aparentemente desaparece. Entretanto, o que desaparece na verdade, é só a individualidade de um ser humano, seu corpo. Como somos definidos também através das nossas ligações com os outros, o lado social do indivíduo persiste, em parte, no mundo, até depois de morrer. Morremos sozinhos e deixamos o mundo "inteiro". E ao morrer, não temos mais lembranças dele, ainda que vestígios de nós permaneçam no mundo. Assim, o indivíduo se torna parte da história.

O fato de sabermos de nossa mortalidade é um fato fundamental da cultura, que pode servir não apenas como explanans, mas também como explanandum na questão "O que é o homem?". Como explanans, a pergunta há de ser reformulada assim: "O que significa a morte para o homem?". Atrás dessa reformulação esconde-se o pensamento de que o fato de se ter consciência da própria mortalidade é a diferença fundamental entre os seres culturais e não-culturais, ou seja, a cultura desenvolve-se porque sabemos que morreremos. Não penetrarei na questão de como a morte pode ser explicada fora das prerrogativas biológicas; e talvez a pergunta seja "metafísica" demais para ser respondida.

A morte pode desempenhar várias papéis diferentes, na explicação de fatos culturais. Ela pode servir como explanandum, por exemplo, da religião ou da guerra, pois trata-se de tentativas de se superar a transitoriedade do indivíduo ou de se valorizar um conjunto dado (uma crença, uma nação) acima do indivíduo. É o medo de morrer e a pergunta a respeito daquilo que vem depois da morte, que levam o homem a crer na metafísica; e é a religião institucionalizada que possibilitou o surgimento, em grande parte do mundo, da arte (mas esta é uma "outra história"). No que diz respeito à guerra, os conflitos entre sociedade e indivíduo revelam-se ainda mais fortemente :o indivíduo luta - voluntariamente ou sem considerar a possibilidade de não lutar - e arrisca sua própria vida, para que uma idéia (uma nação, uma ideologia, uma raça...) não "morra". Neste exemplo fica visível o poder da sociedade sobre o indivíduo.

$\mathrm{Na}$ discussão sobre individualidade e sociabilidade, em um outro nível de abstração, a morte pode esclarecer como são comumente confundidos os traços solitários e sociais do ser humano. Uma caraterística fundamental da 
morte já revela uma de suas faculdades: todo ser humano morre, mas morre sozinho, ou seja, o saber é social, enquanto que o acontecimento é individual. Sabemos todos que morreremos, mas não sabemos como é morrer, pois ninguém jamais voltou para relatá-lo. Assim, a morte é uma das ligações entre a solidão e a sociabilidade individual.

Norbert Elias, em seu livro "La soledad de los moribundos" 25 , discorre mais sobre aspectos concretos da morte, ou seja, como se desenvolveu historicamente a relação da sociedade com a morte. Para ele, existe uma repressão individual e social da morte: a primeira funciona seguindo a teoria de Freud $^{26}$, a segunda seguindo os princípios desenvolvidos pelo próprio Elias no "Processo Civilizador" 27.

\section{Resumo}

Não é tarefa fácil resumir uma pesquisa que, além de não ter resultados concretos, não oferece respostas satisfatórias. O que consegui esclarecer no decorrer deste trabalho foram as dificuldades fundamentais em torno de uma pergunta em particular - "Qual é o papel da sociedade na formação do indivíduo?" - ainda que não a tenha respondido. Ao contrário, abriram-se assim novas questões de pesquisa ${ }^{28}$.

Porém, apresentarei a seguir um dos principais pensamentos que este ensaio fez surgir. Vimos que é quase impossível distinguir os conceitos de individualidade e sociabilidade, embora existam campos na vida do ser humano que são dominados de um lado pelo caráter individual, de outro pela situação histórica. A dor, por exemplo, é um sentimento individual, ou seja, a-social. É impossível transmitir o caráter da dor de um indivíduo ao outro; contentamonos assim com metáforas ${ }^{29}$. Também a maneira de se tratar a dor (não só a maneira medicinal mas também social) é dependente da situação histórica. A preponderância dada por Elias ao fator da sociabilidade me parece às vezes exagerada, mas, como já falei na introdução, os esforços dele são, em geral, bastante louváveis para o entendimento de como o indivíduo é formado.

\footnotetext{
${ }^{25}$ Norbert Elias, La soledad de los moribundos, México, 1987.

${ }^{26} \mathrm{Ibid}$., pág. 16-18.

27 "Para decirlo de una vez: la transformación del comportamiento social de los hombres al que se alude cuando se habla en este sentido de la "represión" de la muerte, es un aspecto del empuje civilisador que he investigado más detalladamente en otro sitio." Ibid., pág. 19.

${ }^{28}$ Uma polêmica sobre a ciência em geral utilizaria essa experiência (cotidiana nas ciências humanas) para interpretar a ciência não como uma instituição de aumento de conhecimento, mas como uma terapia ocupacional.

${ }^{29}$ Parece-me que isto vale para todos os sentimentos. Embora o conceito de sentimento refira-se em maior grau ao individualidade, também o sentimento (como o comportamento) "sofre" restrições pela situação histórica. No decorrer do desenvolvimento humano não era sempre possível ter-se, por exemplo, o sentimento de se estar apaixonado.
} 
Fica incompleto este ensaio, assim como todas as tentativas do homem de entender si próprio. Porém, não é inútil tentar sempre de novo; alcançamos assim novos estados civilizatórios. Como o próprio Elias, não vou refletir sobre a questão segundo a qual o processo civilizatório nos tornaria "melhor" ou "pior". Mas uma coisa é certa: nunca viveu e nunca viverá um ser humano solitário, autônomo e isento de necessidades sociais.

É importante evidenciar-se que não existem conceitos universais no que diz respeito ao homem: todos fazemos parte de uma mesma espécie, porém continuamos sendo diferentes. 